\title{
The earliest stages of second language learning: A behavioral investigation of long-term memory and age
}

\author{
Diana Pili-Moss - Lancaster University \\ d.pilimoss@lancaster.ac.uk - pilidiana@gmail.com - \\ @pilimoss
}

\section{Introduction}

The study investigates the extent to which declarative and procedural long-term memory predict receptive language development in the earliest stages of $L 2$ exposure in children and adults. Recent cognitive models of L2 learning have capitalized on the distinction between declarative and procedural memory (e.g., Ellis \& Wulff, 2015; Hamrick et procedural memory (e.g., Ellis \& Wulff, 2015; Hamrick et
al., 2018; Paradis, 2009; Ullman, 2016) or declarative and al., 2018; Paradis, 2009; Ullman, 2016) or declarative and procedural knowledge (e.g., DeKeyser, 2015) to account
for patterns of $L 2$ processing and development. Previous studies with adults have found asymmetries in the engagement of the two memory systems depending on amount of L2 practice (e.g., Hamrick, 2015; Morgan-Short et al., 2014), training conditions (e.g., Morgan-Short, 2007) type of linguistic target (e.g., Antoniou et al., 2016), learning context (e.g., Faretta-Stutenberg \& Morgan-Short, 2017). Although some L1 studies (e.g.. Kidd, 2012) have found a significant effect for procedural memory in child language significant effect for procedural memory in child language
development, no training studies to date have explored the development, no training studies to date have explored the The linguistic targets investigated here include aural sentence comprehension (measured during L2 practice), word order and case marking (measured by an aural grammaticality judgment test [GJT] administered at the end of practice).

RQ1: To what extent do declarative and procedural learning ability predict aural comprehension of sentences during L2 practice in children and adults?

RQ2: To what extent do declarative and procedural learning ability predict L2 gains in word order and case marking (as measured by a GJT) in children and adults?

\section{Materials and methods}

Forty L1 Italian 9 year olds and 36 adults $(M=22 ; S D=$ 3.7) were incidentally exposed to BrocantoJ (a Japanesebased version of Brocanto2, Morgan-Short, 2007) in the context of a computer board game similar to draughts. After vocabulary training (including 4 tokens names, 4 moves [verbs], 2 adjectives for the tokes' shapes, 2 adverbs [directions], but excluding the case markers) the participants were shown game moves on the computer and simultaneously exposed to the aural sentence stimuli that described them. The exposure (144 sentences) was distributed over six blocks (B) and delivered over three consecutive days (B1, B2-3, B4-6). After each exposure block the participants played a computer game, which consisted in performing novel moves following an aura consisted in pera example of a BrocantoJ sentence a participant would hear associated to the game scenario below:

Troise blomi li neimo blomi lu zeima nima [Round blom NOM square blom ACC horizontally capture] 'The round blomi piece captures the square blomi piece horizontally'

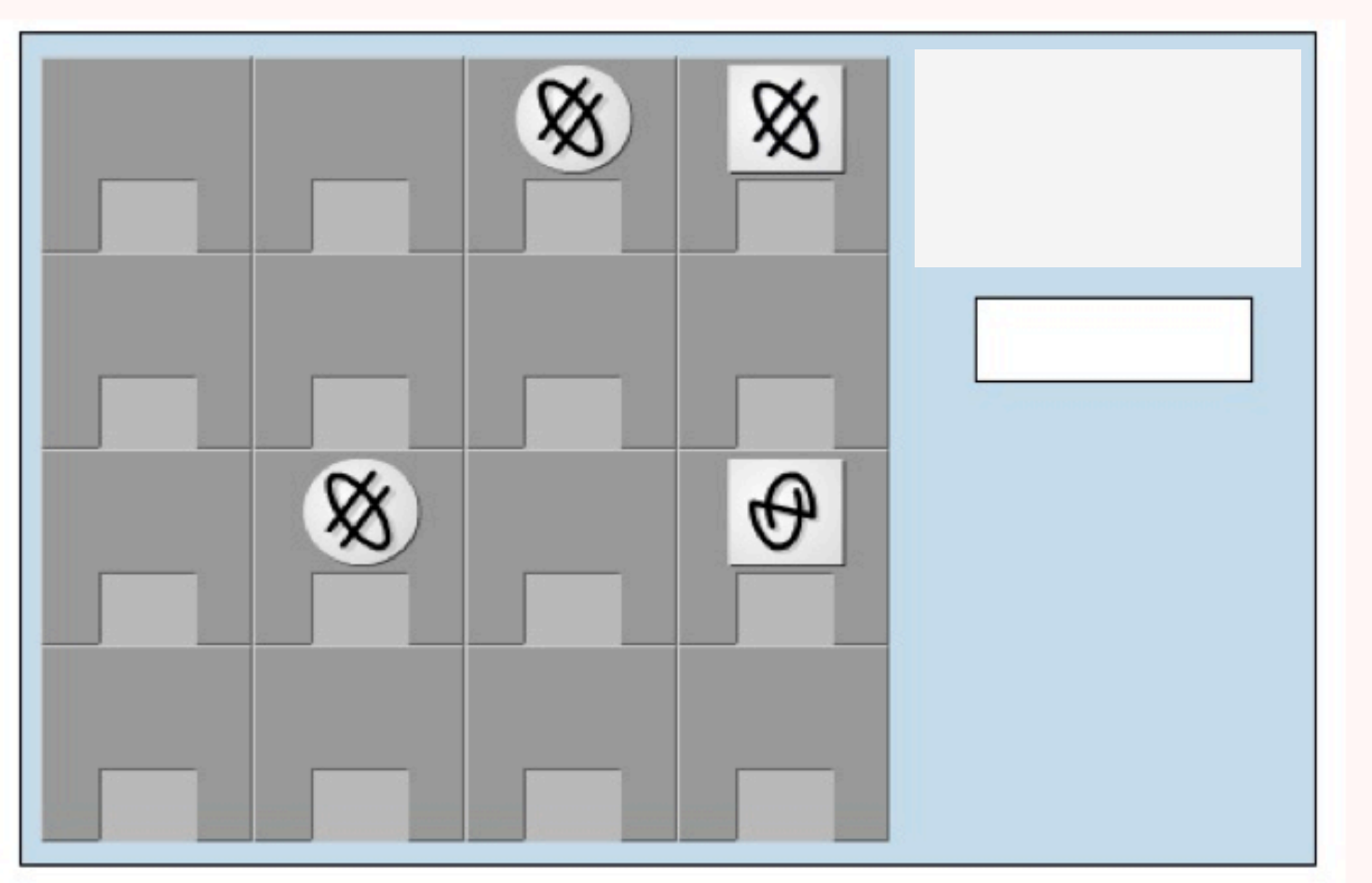

$\varnothing$ blomi

(๑) vode

Cognitive and outcome measures

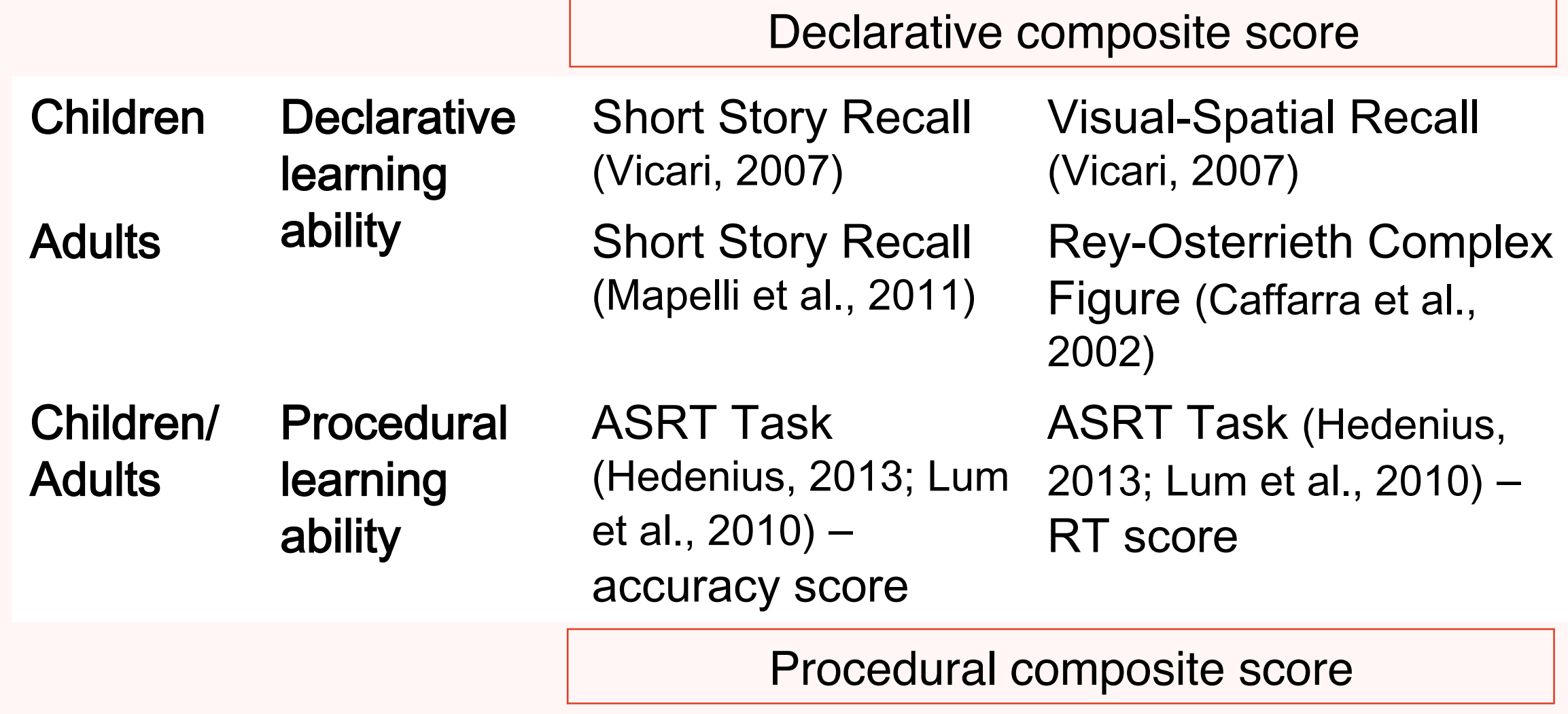

Trial accuracy in the computer game was used as a measure of sentence comprehension during practice. The aural GJT administered at the end of practice included 28 experimental trials, half of which ungrammatical, probing word order (8 items) and case (6 items)

\section{Results}

L2 practice

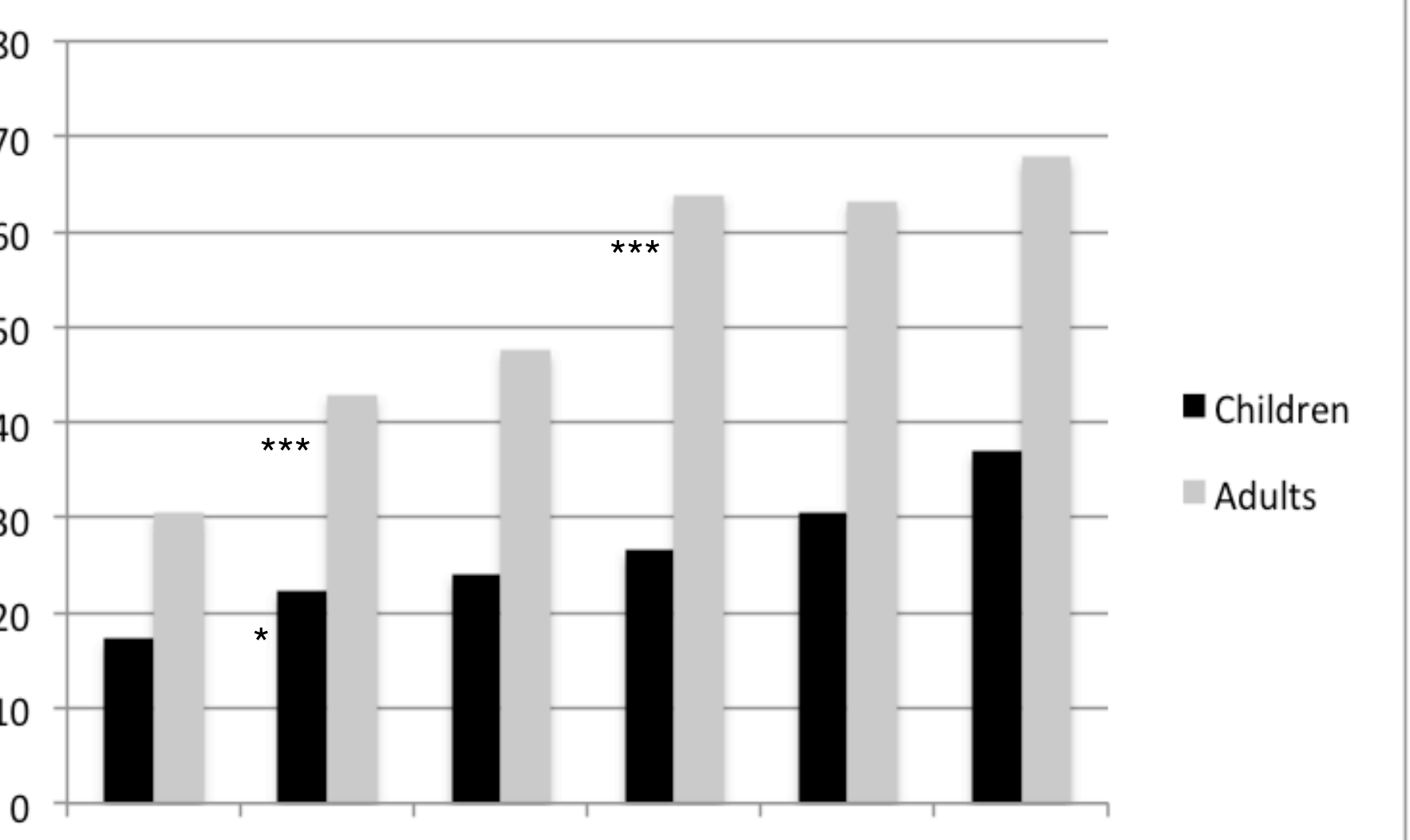

Figure 1. Child and adult rate of learning during L2 practice children

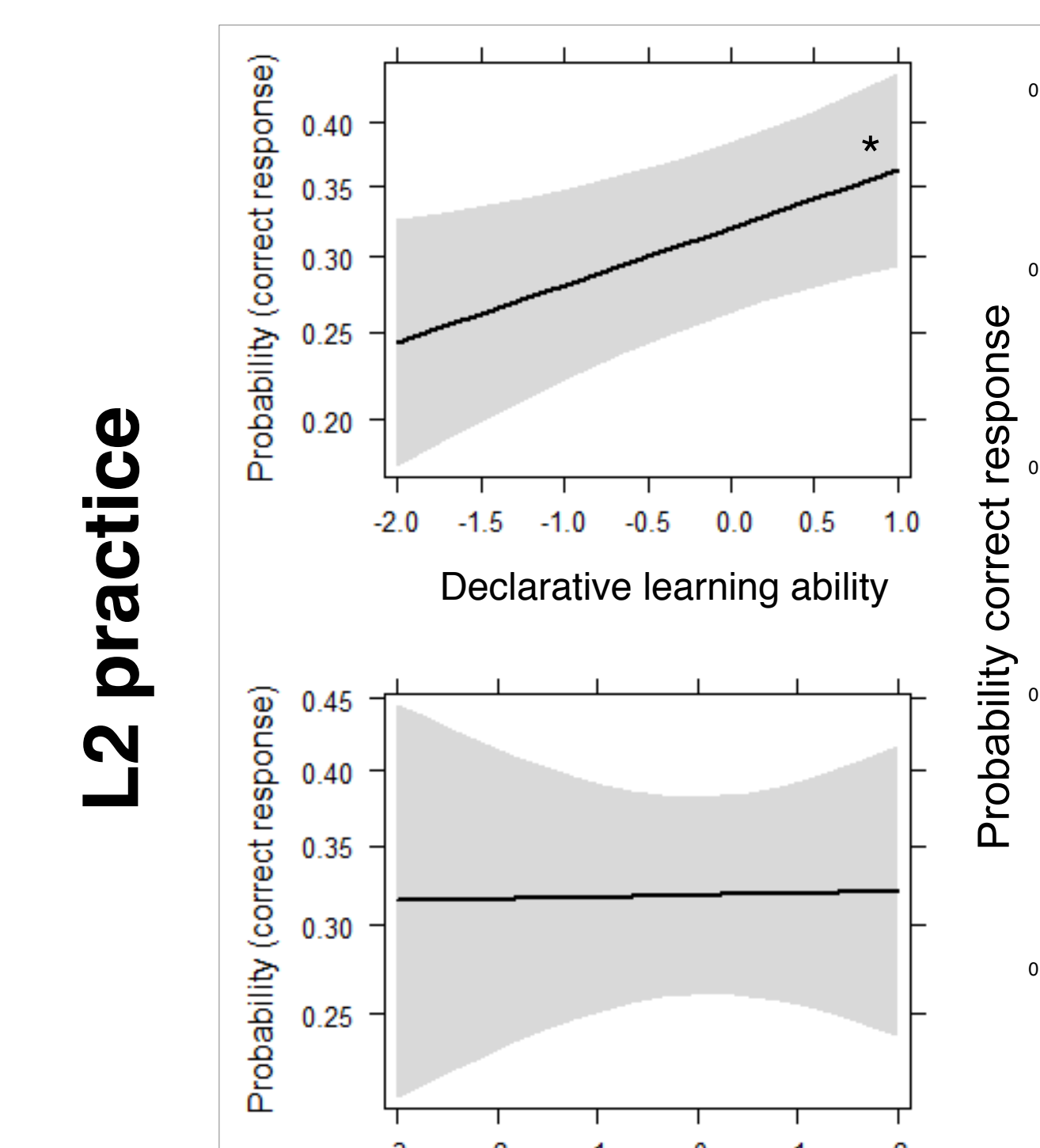

Procedural learning ability Procedural learning ability Figure 3 . Effects of declarative and procedural learning ability in child L2
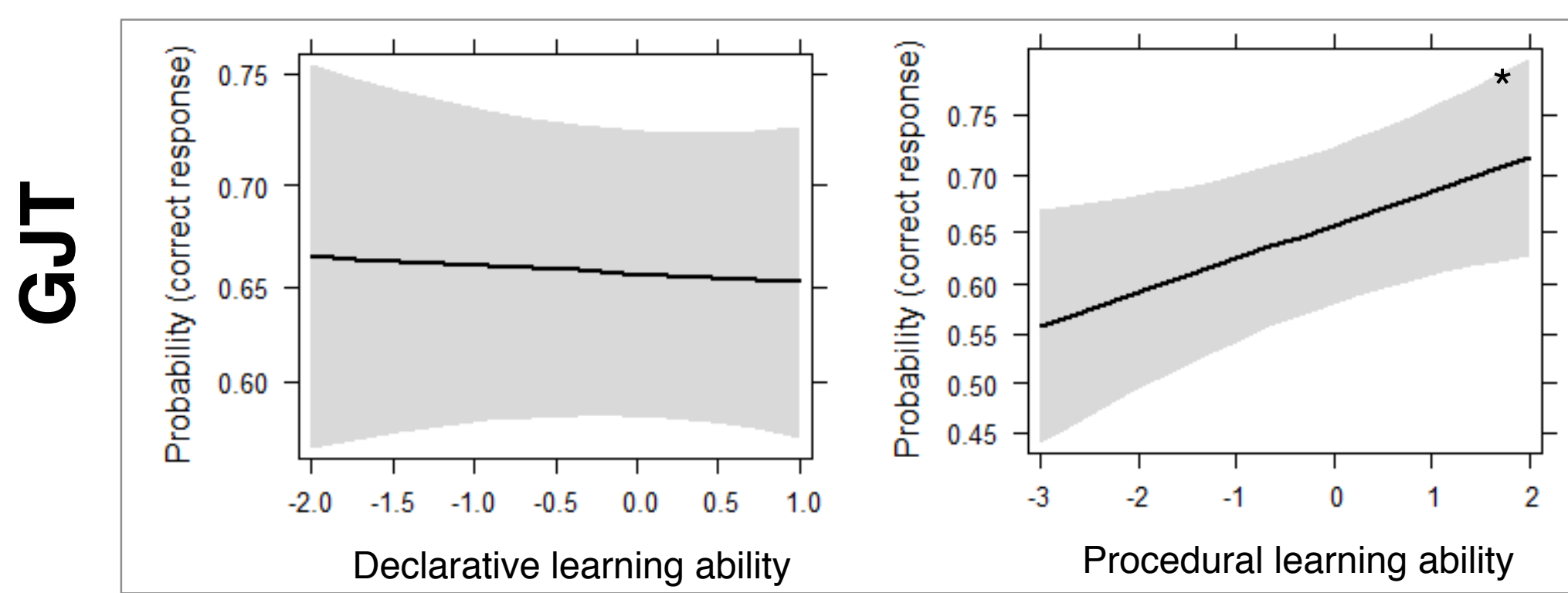

Figure 5.
child GJT.

A mixed effects model fitted to the child GJT data returned a nonsignificant effect for declarative learning ability and a significant positive effect for procedural learning ability $(\beta=0.29, z=2.57, p<.05)$. By contrast, in the case of adults, declarative learning ability was a $(\beta=-0.67, z=-2.36, p<.05)$

\section{Conclusions}

(1) Overall, L2 attainment and rate of learning in L2 practice were significantly higher in adults compared to children. Gains were incremental in children, whilst they were consistently significant between sessions in adults.

(2) Adult results support findings in previous studies conducted in similar paradigms but with participants with a different L1. Specifically, they confirm significant effects for declarative learning ability and

nonsignificant effects for procedural learning ability in the earliest stages of $L 2$ development, when this is measured via a GJT (e.g., Morgan-Short et al., 2014)

(3) Procedural learning ability appears to have a more prominent role in child early $L 2$ development, compared to adult early L2 development. This was evidenced in the GJT, as well as during L2 practice. These findings complement previous L1 research with children (e.g., Kidd, 2012) extending the role of procedural learning ability to the $L 2$.

(4) Differences between L2 language practice and the GJT emerged with regard to the effect of declarative learning ability. These differences may be due to an effect of type of task.

\section{Selected references}

Hamrick, P., Lum, J. A. G., \& Ullman, M. T. (2018). Child first language and adult second language are both tied to general-purpose learning systems. Proceedings of the National Academy of Sciences, 115(7), 1487-1492.

Kidd, E. (2012). Implicit statistical learning is directly associated with the acquisition of syntax. Developmental Psychology, 48(1), 171-184.

Morgan-Short, K., Faretta-Stutenberg, M., Brill-Schuetz, K.A., Carpenter, H. \& Wong P.C.M. (2014). Declarative and procedural memory as individual differences in second language acquisition. Bilingualism: Language and Cognition, 17, 56-72.

Ullman, M. T. (2016). The declarative/procedural model: A neurobiological model of language learning, knowledge and use. In G. Hickok, \& S. A. Small (Eds.), The neurobiology of language (pp. 953-968) Elsevier.

How to cite this poster:

Pili-Moss, D. (2018). The earliest stages of second language learning: A behavioral investigation of long-term memory and age. Poster presented at the LEAD Summer School, July $25^{\text {th }}$, University of Tuebingen, Germany. 